\title{
Brucella abortus ure2 region contains an acid-activated urea transporter and a nickel transport system
}

\author{
Félix J Sangari*, Ana M Cayón, Asunción Seoane and Juan M García-Lobo
}

\begin{abstract}
Background: Urease is a virulence factor that plays a role in the resistance of Brucella to low $\mathrm{pH}$ conditions, both in vivo and in vitro. Brucella contains two separate urease gene clusters, ure 1 and ure2. Although only ure 1 codes for an active urease, ure 2 is also transcribed, but its contribution to Brucella biology is unknown.

Results: Re-examination of the ure2 locus showed that the operon includes five genes downstream of ureABCEFGDT that are orthologs to a nikKMLQO cluster encoding an ECF-type transport system for nickel. ureT and nikO mutants were constructed and analyzed for urease activity and acid resistance. A non-polar ureT mutant was unaffected in urease activity at neutral $\mathrm{pH}$ but showed a significantly decreased activity at acidic $\mathrm{pH}$. It also showed a decreased survival rate to $\mathrm{pH} 2$ at low concentration of urea when compared to the wild type. The nikO mutant had decreased urease activity and acid resistance at all urea concentrations tested, and this phenotype could be reverted by the addition of nickel to the growth medium.
\end{abstract}

Conclusions: Based on these results, we concluded that the operon ure2 codes for an acid-activated urea transporter and a nickel transporter necessary for the maximal activity of the urease whose structural subunits are encoded exclusively by the genes in the ure 1 operon.

\section{Background}

Urease catalyzes the chemical hydrolysis of the urea molecule into $\mathrm{CO}_{2}$ and ammonia. These equilibrate in water causing a rise of the $\mathrm{pH}$ of the medium. Accordingly, bacterial ureases serve two main purposes: to neutralize acidic conditions, and to provide a source of assimilable nitrogen.

Pathogenic bacteria exploit urease activity in different ways along the infectious process. In Brucella spp, as well as in Helicobacter pylori, Klebsiella and Yersinia, urease allows bacteria to survive the acidic conditions encountered in the stomach during the gastrointestinal infection [1-5]. The role of bacterial ureases in infectious disease has been recently reviewed [6].

Ureases are complex enzymes generally composed of three structural subunits (UreABC). To assemble a func-

\footnotetext{
* Correspondence: sangarif@unican.es

1 Departamento de Biología Molecular, Universidad de Cantabria, and Instituto de Biomedicina y Biotecnología de Cantabria (IBBTEC), UC-CSIC-IDICAN, Santander, Spain

Full list of author information is available at the end of the article
}

tional urease, the cooperation of several accessory proteins is required (UreEFGD) and, as a consequence, large gene clusters are needed to encode for functional ureases. Brucella contains two urease operons, both located in chromosome I. The Brucella ure1 operon contains the genes ureDABCEFG, and the Brucella ure 2 locus shows the structure ureABCEFGDT [1]. The last gene of ure2, ureT, encodes a putative urea transporter homologous to Yut from Yersinia pseudotuberculosis [7]. Most Brucella species show a strong urease activity, derived from ure1 but not from ure2, and this activity is responsible for the ability of Brucella to survive stomachal transit and to establish a systemic infection $[1,2]$. B. ovis is not able to infect the host by the gastrointestinal route, a fact that has been linked to its lack of urease activity [8]. Furthermore, purification and characterization of urease from $B$. suis showed the presence of urease subunits from ure 1 but not from ure2 [9]. Strikingly, ure2 genes are transcribed in vivo [1,2], suggesting that they play a role in Brucella. 
Urease is one of the few enzymes known to contain nickel atoms in their active centers [10]. Because of this, the bacteria needs nickel uptake systems and a mechanism to incorporate the metal into the active center of the enzymes. Transition metal atoms are toxic and they cannot be free in the bacterial cytoplasm. Nickel should be delivered from the transport systems to chaperones that store the metal until needed for assembly. Chaperones and folding-assisting proteins are encoded by the urease accessory genes ureDEFG that form part of both Brucella urease operons. High affinity nickel transport systems of bacteria fall into several categories: the ATP-binding cassette $(\mathrm{ABC})$ systems represented by NikABCDE of E. coli [11], the newly described Energy-Coupling Factor (ECF) transporters like NikMNQO [12] and secondary transporters from different families that include $\mathrm{NiCoT}$ [13], UreH [14], and HupE/UreJ [14,15]. The ECF transporter NickMNQO consist of substrate-specific module (S components, NikMN), which are integral membrane proteins, and an energy-coupling module that contains an ATPase typical of the ATP binding cassette (ABC) superfamily (A component, NikO) and a characteristic transmembrane protein ( $\mathrm{T}$ component, $\mathrm{NikQ}$ ). It may contain additional components like NikL, which is an integral membrane protein, or NikK, a periplasmic protein $[12,16]$. In Brucella suis, a nickel ABC transporter coded by the nikABCDE gene cluster has been identified. This gene cluster has been shown to contribute towards the urease activity of the bacteria when $\mathrm{Ni}$ ions are chelated with EDTA in the growth medium, but not in control media without EDTA. This implies, as noted by the authors, that there is at least another functional nickel transport system in this bacteria [17].

Urease activity is also dependent on the supply of urea. There are at least three urea uptake systems in bacteria. The ABC-type urea transporter is energy-dependent and requires ATP to transport urea across the cytoplasmic membrane. The other two urea transporters, Yut and UreI, are energy-independent and appear to be channellike structures that allow urea to enter the cytoplasm through a pore powered by a favorable concentration gradient that is maintained by rapid hydrolysis of the incoming urea by intrabacterial ureases. The recent determination of the crystal structure of the Desulfovibrio vulgaris urea transporter [18] confirms the existence of an unoccluded channel for urea, with a 'molecular coinslot' mechanism that allows urea to pass through the transporter in preference to other small molecules. This selective filter consists of two hydrophobic slots in series, just wide enough to permit the coin-shaped urea molecule to enter. Each slot is formed by two phenylalanine amino-acid residues, an "oxygen ladder" lying along one side of the slot, and several hydrophobic phenylalanine and leucine residues lining the pore opposite to each of the oxygen ladders. The oxygen ladder provides electrostatic interactions for the urea molecules, helping to extract them from the aqueous environment outside the channel. The urea channels are composed of different numbers of membrane-spanning helices (six for Helicobacter UreI, ten for Yersinia Yut), that in the case of Yut and UreT form two repeated domains linked by a large periplasmic loop. However, the most important difference between UreI and Yut is their response to acidic $\mathrm{pH}$. While Yut shows similar activity at a range of different $\mathrm{pH}$ [7], UreI shows a 6- to 10 -fold activation at $\mathrm{pH} 5.0 \mathrm{com}$ pared to $\mathrm{pH} 7.5$ [19]. The presence of protonable residues (histidines or carboxylates) in the periplasmic loops of UreI seems to be responsible for this activation, and the mechanism of proton-gating presumably is a conformational change in the membrane domains of UreI induced by a change in the state of protonation of those residues [20]. Both nickel and urea transport systems are required in order to reach maximum levels of urease activity.

The evidence presented here shows that the urease operon ure 2 includes genes for the transport of urea and nickel, and that these genes are expressed and active, contributing to urease activity and to resistance to the acidic conditions present in the oral route of infection.

\section{Results}

\section{Evidence of transcription and redefinition of the ure2 operon of Brucella abortus 2308}

We have previously reported that the Brucella urease operon ure 2 did not contribute to the urease activity of the bacteria [1]. The ure 2 operon of Brucella abortus 2308 was considered to be composed of eight genes ureABCEFGDT (BAB1_1376-1383). A re-evaluation of the chromosomal region suggested that some genes immediately downstream of ureT could be part of the same operon, because: 1) the distance between ureT and the contiguous gene nikM was only $26 \mathrm{bp}, 2$ ) there was a good ribosome binding site upstream the putative start codon of nikM, and 3) there was no obvious transcriptional terminator between the two genes. PCR amplification of reverse transcribed Brucella RNA using the pairs of primers indicated in Table 1 was conducted to assess the continuity of the transcript until we reached the first gene annotated on the opposite strand (BAB1_1389). Genomic DNA and total RNA were used as positive and negative controls, and the results are shown in Figure 1. Five additional genes (BAB1_1384-1388) were found to be cotranscribed with the first eight genes, and their functional gene annotation was performed using the SEED comparative genomics resource [21]. The proposed role of these genes (nikKMLQO) was to code for a nickel transport system belonging to the novel ECF class of modular transporters [12]. According to this classification, NikM would be the substrate-specific component, 


\section{Table 1: Oligonucleotides}

\begin{tabular}{|c|c|c|}
\hline RT PCR & & Gene set \\
\hline RT_BAB1_1374_BamHI.F & GGATCCACACGCGATTTCCTTTCATC & 1 \\
\hline RT_ureA2_BamHI.R & GGATCCCATCACCTCTTCGACGGTTT & 1,2 \\
\hline RT_BAB1_1375.F & AAGGTCCTGCCAGTACAACG & 2 \\
\hline RT_ureA2.F & AAACCGTCGAAGAGGTGATG & 3 \\
\hline RT_ureC2.R & CGCAGATCCTTCTCGATTTC & 3 \\
\hline RT_ureC2.F & ACAGTCGATCTCGCTCAACC & 4 \\
\hline RT_BAB1_1381.R & CTTGATAAGGATTGGCACGA & 4 \\
\hline RT_BAB1_1381.F & ACCTGATCCGTGAAAACGTC & 5 \\
\hline RT_BAB1_1383.R & GAAAGAACAGTCCCGTCAGC & 5 \\
\hline RT_BAB1_1383.F & GGATACAACCAAGCCTGCAT & 6 \\
\hline RT_BAB1_1386.R & GGCATTGCGGATGATAAGTT & 6 \\
\hline RT_BAB1_1386.F & GCTITITCTCTGGGCCAAAT & 7 \\
\hline RT_BAB1_1388.R & GACAGGGAAAGCTTGTCGAG & 7 \\
\hline \multicolumn{3}{|l|}{$\Delta u r e T$} \\
\hline U_BMEI0642_Xbal.F & TCTAGAGACCCAGACCATAACGCTTG & \\
\hline U_BMEI0642_BamHI.R & GGATCCCTGCCATGGAGGCCTCCT & \\
\hline BMEI0642.F & $\begin{array}{l}\text { AGGAGGCCTCCATGGCAGGGATCCCCTGA } \\
\text { GCCTGATTTCTGGA }\end{array}$ & \\
\hline D_BMEI0642_Pstl.R & CTGCAGGACCGATCCGTCATTGACAT & \\
\hline \multicolumn{3}{|l|}{$a p h T$} \\
\hline$a p h T . F$ & ATACTGCAGATTAGAAAAACTCATCG & \\
\hline aphT.R & TCACACAGGAAACAGCTATG & \\
\hline
\end{tabular}




\begin{abstract}
$\Delta n i k O$
BAB1_1388 Xbal.R

RT_BAB1_1388.R

BAB1_1388 Bg/ll.F

BAB1_1388 Pstl.R

CTGCATTATGTCGAG

while NikQ and NikO would be the transmembrane and ATPase components, respectively, of the energizing module. NikK and NikL would be additional components. Their role in nickel transport is also supported by the genomic context, as urease is a nickel-containing enzyme, although we could not find other supporting evidence (e.g. NickR-binding sites in the region). The complete ure 2 operon is thus composed of thirteen genes putatively involved in three different functions, namely urease production, urea transport, and nickel transport.
\end{abstract}

GACAGGGAAAGCTTGTCGAG

ACGTCTGCAGCATTATCGATAGCGGCCTTG

ACGTTCTAGACAATATCTGCGTGCTCTCCA

CTCGACAAGCTITCCCTGTCAGATCTCCAC

\section{Construction of chromosomal mutants in the ure 2 operon}

In order to analyze the impact of the ure 2 genes on urease activity, we constructed three mutants as described in the Methods section: i) a polar mutant created by replacing part of $u r e T$ with a kanamycin resistance gene that has a transcriptional termination signal $(\Delta u r e T p)$, ii) a nonpolar mutant lacking the aph transcriptional terminator, which only affects ureT function ( $\Delta u r e T)$, and iii) a $\Delta n i k O$ mutant, affecting the ATP binding protein of the putative nickel transport system encoded by nikO, the last gene of the operon, and predicted to have the biggest impact on the correct function of the transporter while still maintaining basal activity [16].

\section{Urease activity of the different ure2 mutants}

Urease activity was measured in crude protein extracts from the mutants and the wild type strain. The results in Figure 2A show that extracts of both the $\Delta u r e T p$ and $\triangle n i k O$ mutants had their urease activity reduced to about $50 \%$ of the activity observed in the wild type strain 2308 , while the urease activity was rather unaffected in the $\Delta u r e T$ mutant. To confirm that the observed effects were direct consequence of the introduced mutations, mutants were complemented with plasmids carrying either ureT or $n i k O$ genes. Mutants $\Delta u r e T p$ and $\triangle n i k O$ were complemented by the nikO containing plasmid pFJS245 (Figure $2 \mathrm{~A}$ ), but no effect on urease activity was observed when pFJS243 (containing ureT) was used to complement the $\Delta u r e T p, \Delta u r e T$, or $\Delta$ nikO mutants (data not shown).

\section{Effect of nickel addition on urease activity of different Brucella strains}

Nickel and cobalt are transition metals that can share the same bacterial import systems [16]. The genes nikKM$L Q O$, currently annotated in the Brucella genomes as components of a cobalt transport system, are found downstream of the ure 2 genes, and form part of the same operon, so we tested whether they were involved in the transport of nickel, which is essential for urease activity. The addition of an excess of nickel in the form of $\mathrm{NiCl}_{2}$ would supply the metal needed for urease assembly in spite of the inactivation of the nik transport system. We tested the urease activity of the different strains grown in the presence or absence of $0.5 \mathrm{mM} \mathrm{NiCl}{ }_{2}$ in the culture medium. The results in Figure 2B indicate that the urease activity of all the mutants reverted to normal values when the culture medium was supplemented with nickel, thus confirming the suspected role of the products of the nik genes of the ure 2 operon in nickel transport. These results are also a further evidence for the extension of the operon until the $n i k O$ gene; that is a polar ureT mutation has a lower urease activity than the corresponding nonpolar mutant, and identical activity to that of the nikO mutant, suggesting that the observed phenotype is the result of a polar effect on the genes downstream of ureT.

\section{Effect of $\mathrm{pH}$ on urease activity in intact cells}

Brucella urease assayed in vitro shows a $\mathrm{pH}$-dependent activity that is maximal at $\mathrm{pH} 7.3$ [1]. When urease activity was assayed in intact $B$. abortus 2308 cells, the activity was higher at low $\mathrm{pH}$ values and dropped to near one third as the $\mathrm{pH}$ of the medium reached a value of 6 (Figure 3). $\Delta$ ureT intact cells showed very similar activity to wild type cells at $\mathrm{pH}$ values above 6 , but they lost the acid-dependent induction of urease activity at lower $\mathrm{pH}$ values. The increased urease activity of the $\Delta u r e T$ mutant due to enhanced urea uptake at low $\mathrm{pH}$ could be restored by complementation with the ureT containing plasmid pFJS243. 


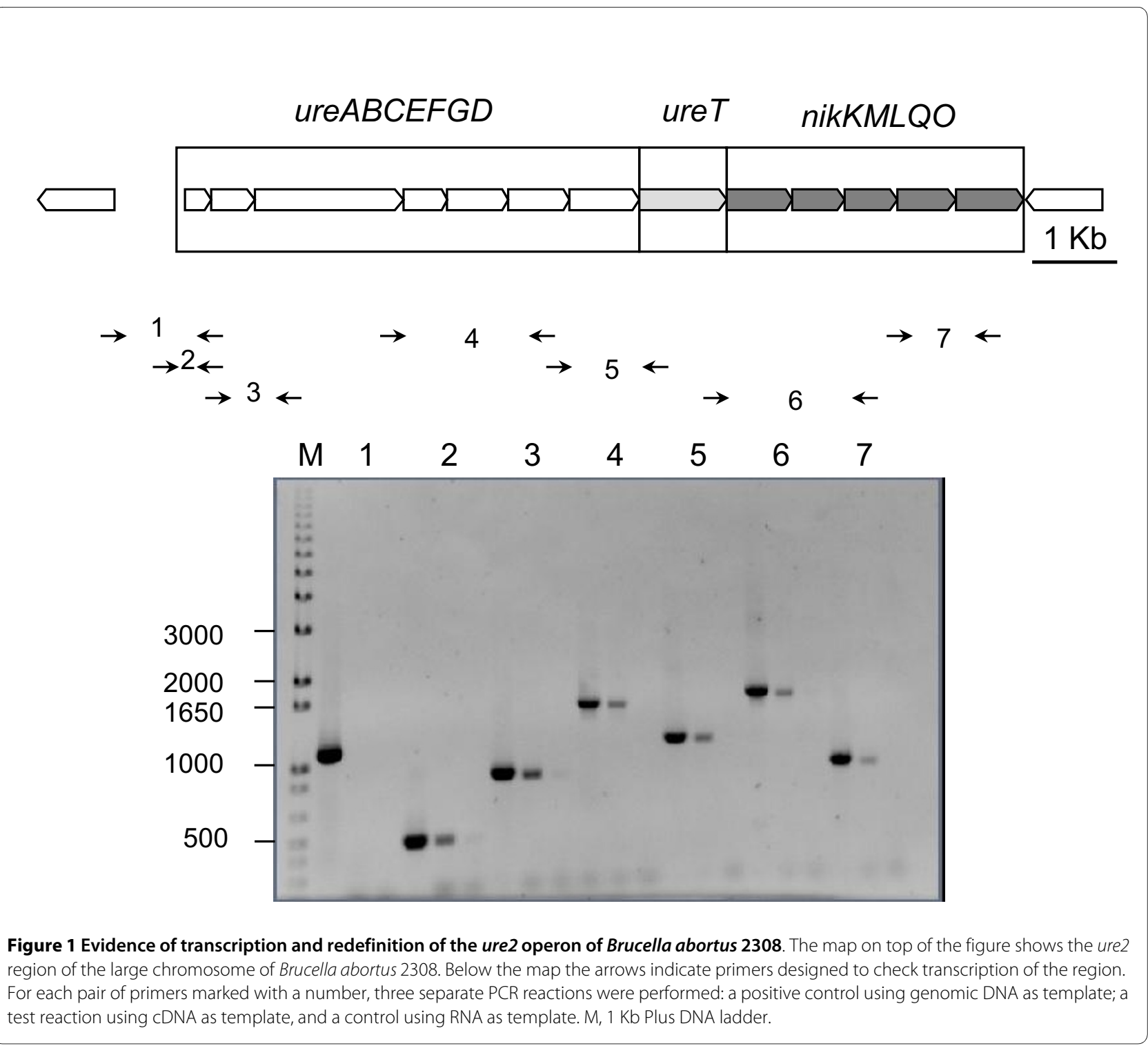

Effect of urea concentration on urease activity in intact cells As the observed results were consistent with UreT being a urea transporter, 2308, $2308 \Delta u r e T$, and $2308 \Delta u r e T$ (pFJS243) were exposed for one hour to increasing concentrations of urea ( $\mathrm{pH} 4.2)$. The urease activity of both the wild type and the complemented strains increased steadily with the available urea. However, the $\Delta u r e T$ mutant showed significantly lower activities at all the urea concentrations tested, except for 75 and $100 \mathrm{mM}$, where urease activity reached wild type levels (Figure 4), presumably because membrane diffussion surpasses carrier mediated transport at these urea concentrations.

\section{In vitro susceptibility of Brucella to acid $\mathrm{pH}$}

It has been shown that under long (15 $\mathrm{min}$ ) exposures to highly acidic environments ( $\mathrm{pH} 2.0$ ), urease activity in the presence of urea in the medium enables Brucella survival $[1,2]$. The $\Delta u r e T$ mutant showed a susceptibility to acid significantly higher than the wild type but lower than the $\Delta u r e T p$ and nikO mutants at low concentrations of urea $(5-10 \mathrm{mM})$. At $50 \mathrm{mM}$ urea the $\Delta u r e T$ mutant was as resistant as the parental strain, while the $\Delta u r e T p$ and nikO mutants remained significantly susceptible (Figure $5)$.

The susceptibility to low $\mathrm{pH}$ of the mutant nikO was completely reversed by complementing it with pFJS245 in trans. The mutant $\Delta u r e T p$ could not be complemented in this assay with either pFJS243 or pFJS245 (data not shown). However the acid sensitivity of both mutants could be compensated by the addition of $\mathrm{NiCl}_{2}$ to the growth medium (data not shown). 

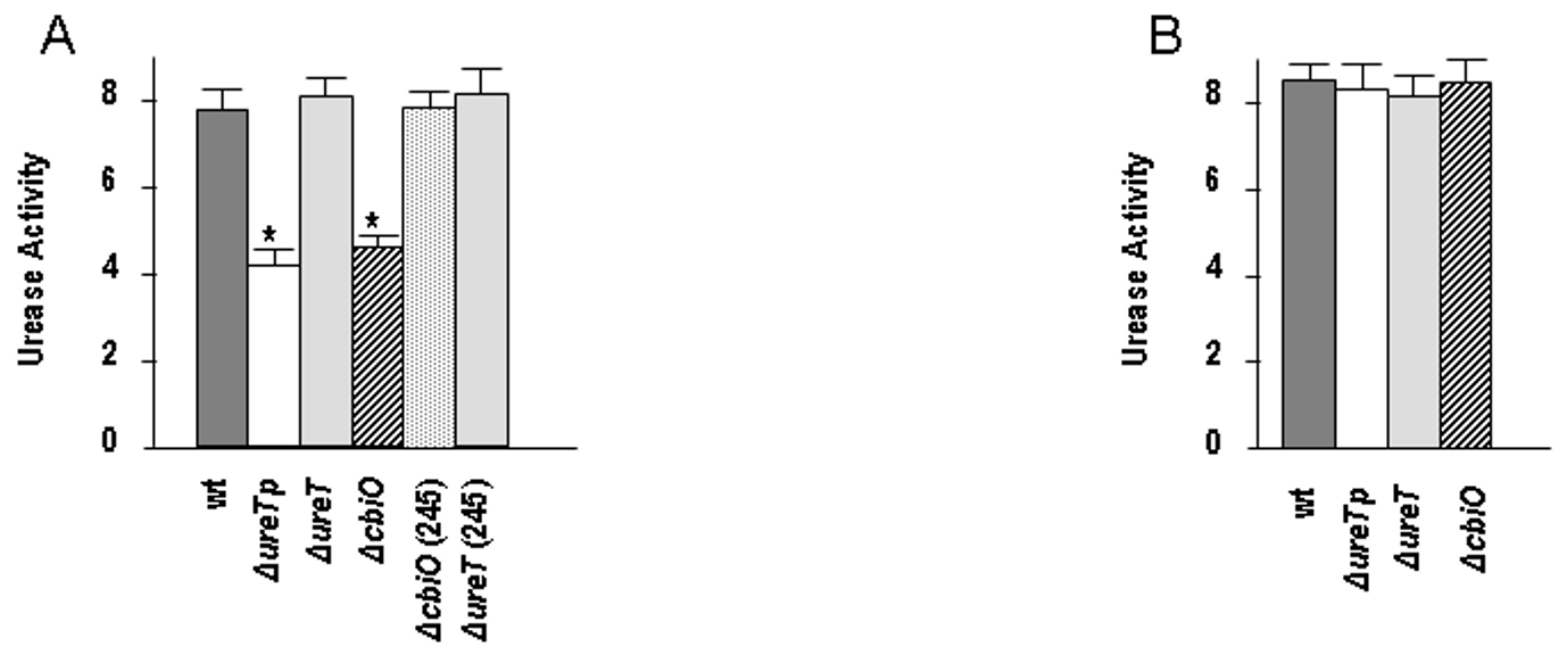

Figure 2 Urease activity of B. abortus 2308-derived strains. Urease activity was determined in bacterial extracts obtained from the indicated strains and growth conditions, and expressed in $\mu \mathrm{mol}$ of $\mathrm{NH} 3 \mathrm{~min}^{-1} \mathrm{mg}^{-1}$ protein The experiments were performed by triplicate with three technical measures per replica. The data shown correspond to one representative experiment and the error bar indicates the standard deviation. An unpaired $\mathrm{t}$-test was performed to determine if the urease activity of each mutant was significantly different than the corresponding wild type control. A. Protein extracts from cultures of the indicated strains grown in BB. B: Protein extracts from cultures grown in BB supplemented with $0.5 \mathrm{mM} \mathrm{NiCl}_{2} \cdot{ }^{*}$ indicates $p<0.05$.

\section{Discussion and Conclusions}

The presence of two operons encoding urease in the genome of Brucella had already been reported. Evidence from our laboratory and elsewhere [1,2,9] showed that only urease from ure1 contributed towards the urease activity of Brucella. Explanations based on a degeneration

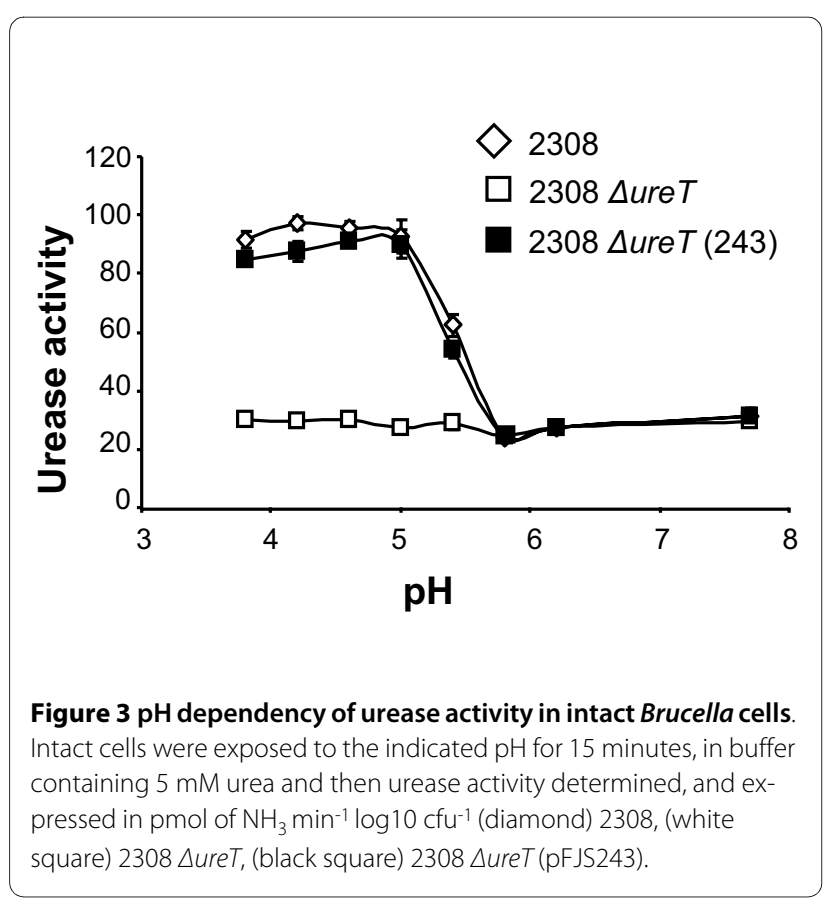

in the sequence of ure 2 were ruled out and early evidence suggested that ure 2 genes were transcribed [1,2]. Accordingly, we suggested that ure 2 should have some function that ensures its conservation in the genome of Brucella [1].

In this work, we analyzed the transcription of the ure 2 operon by RT-PCR, confirming that the ure 2 genes are transcribed and that transcription goes beyond ureT, up to the gene nikO (BAB1_1388) (Figure 1).

While our RT-PCR experiment did not show a fulllength transcript, it demonstrated the existence of messenger RNA molecules containing both ureT and ureD and also ureT and nikM. Furthermore, the introduction of

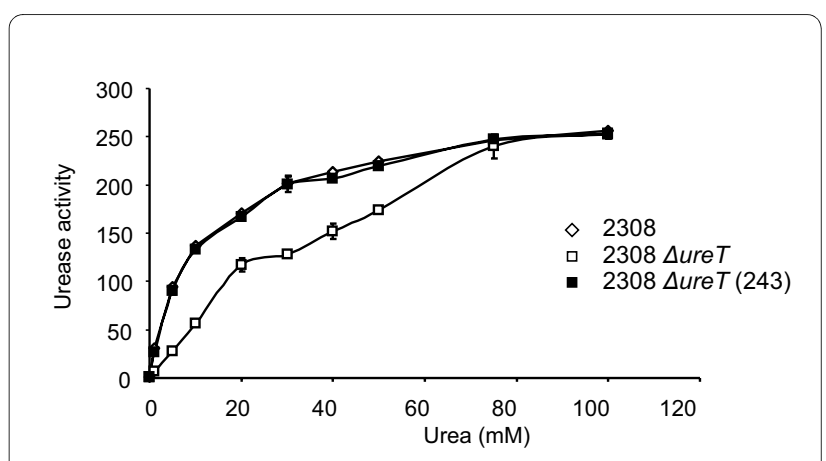

Figure 4 Urease activity in a urea gradient. Intact cells exposed to buffer pH 4.2 with increasing amounts of urea. (diamond) 2308, (white square) $2308 \Delta$ ureT, (black square) $2308 \Delta$ ureT (pFJS243). 


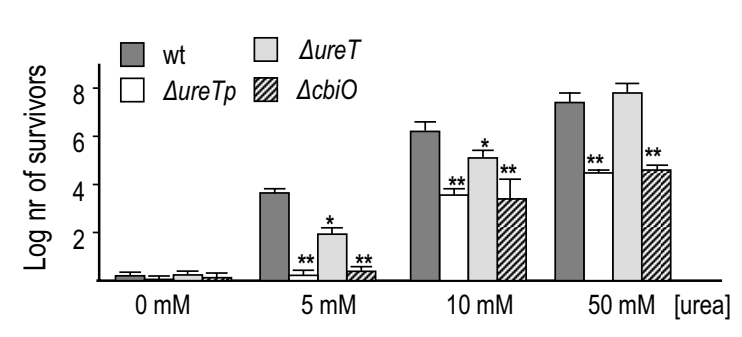

Figure 5 Survival of $B$. abortus urease mutants to acid exposure. $\log n^{\circ}$ of bacteria surviving an acid shock of 30 minutes at $\mathrm{pH} 2.0$ in the presence of different amounts of urea. The arithmetic media from three separate experiments was plotted with standard deviations. An unpaired t-test was performed to determine if survival of each strain was significantly different than the corresponding wild type control. * indicates $p<0.05,{ }^{* *} p<0.01$

a polar mutation in ureT had different effects than the introduction of a non polar mutation in the same gene, and the polar effects could be explained by the absence of activity of distal nik genes. Pooling this data, the most plausible explanation is that all the genes in the revised ure 2 cluster form a single transcriptional unit that we have termed ure2ACBEFGDTnikKMLQO. We cannot rule out the possibility of secondary promoters existing in this region.

By compairing the mutant strains to the wild type progenitor we observed that there was no significant difference in urease activity between protein extracts from $B$. abortus 2308 and the $\Delta u r e T$ mutant, but the analysis of urease activity in intact cells at different $\mathrm{pH}$ 's revealed that, while the wild type strain showed a sharp increase in urease activity at $\mathrm{pH}$ values lower than 5.8 , the activity of the $\Delta u r e T$ mutant remained unchanged. The amount of active urease in protein extracts from the $\Delta u r e T$ mutant was the same as that of the 2308 parental strain, indicating that urease biosynthesis was not affected. However UreT contributes towards urease activity in intact cells by facilitating the access of urea to the cytoplasm. Our results indicate that the urea transporter plays a role at low urea concentrations, equivalent to those encountered in host tissues. At higher concentrations, urea diffusion through the inner membrane probably compensates for the absence of the transporter. Remarkably, the activity of the transporter (measured as urease activity in this case) was $\mathrm{pH}$-dependent. The activity observed at $\mathrm{pH} 5.8$ or higher would be the result of urea diffusing through the inner membrane. That UreT is an acid-activated urea transporter is somewhat surprising, given that its closest homolog, Yut of Y. enterocolitica, is not $\mathrm{pH}$-regulated [7], while the best known example of a proton-gated urea channel, UreI of the gastric pathogen $H$. pylori [20], shares a rather low amino acid sequence identity to UreT. The mechanism of proton-gating has been proposed to be a conformational change in the membrane domains of
UreI induced by a change in the state of protonation of some residues (histidines or carboxylates) in the periplasmic loops. Modelling of UreT, UreI and Yut with TMRPres2D [22] revealed some differences between the protein sequences at the periplasmic loops. While UreI presents a total of fourteen protonable residues, Yut has only three, and UreT possesses seven (data not shown). The higher number of protonable residues of UreT could account for the differences found in acid activation between Yut and UreT. However, the mechanism of urea selectivity is probably the same, as a comparison with the crystal structure of the urea transporter of D. vulgaris shows that all the residues that form the pore are conserved (data not shown). The only one minor difference is that in one of the two urea slots present in UreT, one of the phenylalanines forming the slot is changed to leucine (L201F), and the corresponding leucine in the slot is changed to phenylalanine (F304L) (data not shown).

Since urea uptake is not pH regulated in Yersinia spp, the unrestricted entry of urea would alkalinize the cytoplasm to lethal levels. Yersinia has solved this problem by expressing a urease with an acidic $\mathrm{pH}$-optimum, that has little or no activity at $\sim \mathrm{pH} 8.0$ [5]. Brucella urease has a $\mathrm{pH}$ optimum of 7.3, and although its activity is much lower at $\mathrm{pH}$ 8.0, it is still significant. In this case, the problem of lethal alkalinization is prevented by the existence of a $\mathrm{pH}$-regulated urea transporter that reduces urea uptake to just the amount that diffuses through the inner membrane.

In contrast to the $\triangle u r e T$ mutant, mutants $\triangle u r e T p$ and $\triangle n i k O$ showed around a $40 \%$ decrease in urease activity in cell extracts. Both phenotypes were reversed by complementation of the mutant strains with a nikO-containing plasmid or, alternatively, with high concentrations of nickel in the culture medium suggesting that the amount of active urease in these mutants was limited by nickel availability. Complementation of the urease activity of the $\triangle u r e T p$ mutant with the nikO plasmid was rather surprising if we consider that the mutant should be defective not only in $n i k O$ but also in the other nik genes. Furthermore, the susceptibity to low $\mathrm{pH}$ of the $\Delta$ ureTp mutant was not complemented by the nikO gene in trans, suggesting that other factors may be implicated in the acid resistance phenotype of Brucella.

$\mathrm{NikO}$ is predicted to be the ATPase component of an ECF-type nickel transporter, and its mutation should abolish most of the activity of the transporter. There is another nickel transport system already described in $B$. suis, NikABCDE (10). nikA mutants were not affected in urease activity unless a chelating agent was added to the medium. As both the $\triangle u r e T p$ and $\triangle n i k O$ mutants show lower urease activity than the wild type when grown in standard medium, we concluded that NikKMLQO is the main nickel transport system in Brucella. B. suis nikA 
mutants have an intact NikKMLQO nickel transporter, whose function can override the nikA mutation. In $B$. abortus 2308 by contrast, the single nikO mutation produced a significant decrease in urease activity. Sequence analysis reveals that the three $B$. abortus strains sequenced so far are natural nikA mutants, explaining why the nikO mutation caused such a decrease in urease activity. When supplemented with $500 \mathrm{mM} \mathrm{NiCl}, B$. abortus 2308 showed an increased urease activity, which probably reflects that the nickel content is not optimal in $B$. abortus and that this could be one of the factors that determines a lower urease activity in $B$. abortus when compared to B. suis.

Brucella possesses several genetic resources to cope with its needs of urease. At least three loci, nik, ure 1 and ure 2 play a role in this function. There are also some additional genes, like $c o b T$, that contribute in a yet unknown way to the overall urease activity [1]. As a conclusion, Brucella spp. not only has at least one active urease, but also a specific, proton-gated urea transporter, and two nickel transport systems that contribute to the overall urease activity. While the urease structural genes and nickel transport systems affect the intrinsic urease activity, UreT would not affect it, but would be important for physiological processes such as the resistance to low acid conditions by increasing the efflux of urea into the bacteria, affecting in this way the overall urease activity, specially at low urea concentrations. These are the conditions faced by the bacteria in the gastrointestinal route, that it is been again recognized in the last years as an important route of infection in Brucella [1,2,23,24], reinforcing the idea that urease activity, and the acid resistance that it causes, is important in the life cycle of the bacteria.

\section{Methods}

\section{Bacterial strains and growth conditions}

The bacterial strains and plasmids used in this study are listed in Table 2. B. abortus strains were grown in Brucella broth (BB) or Brucella agar (BA) plates (Pronadisa, Spain). Escherichia coli strains were grown in Luria-Bertani broth (LB) or plates (LA). When required, media were supplemented with the following antibiotics: kanamycin $(\mathrm{Km}) 50 \mu \mathrm{g} / \mathrm{ml}$, ampicillin (Ap) $100 \mu \mathrm{g} / \mathrm{ml}$, or chloramphenicol $(\mathrm{Cm}) 25 \mu \mathrm{g} / \mathrm{ml}$, or with $500 \mu \mathrm{M}$ of $\mathrm{NiCl}_{2}$. Mating mixtures were plated in BA plates made selective with Brucella Selectavial, (BAF) (MAST Diagnostics, UK). All experiments with live Brucella were performed in a Biosafety Level 3 facility at the Department of Molecular Biology of the University of Cantabria.

\section{Molecular techniques}

DNA manipulations were performed according to standard techniques [25]. Restriction enzymes were pur- chased from Fermentas, and primers were purchased from Sigma-Aldrich. DNA fragments were amplified by PCR from B. abortus 2308 genomic DNA extracted as previously described [26]. High-fidelity PCR was performed using Vent polymerase (New England Biolabs), and standard PCR was performed using Taq (Qiagen). PCR products were purified using GenElute ${ }^{\mathrm{Tw}}$ PCR CleanUp (Sigma). Amplified products were cloned in pGEM $^{\circ}$-T Easy (Promega) or pJET1.2 (Fermentas) depending on the polymerase used. The DNA sequence of the final plasmids was determined to rule out mutations introduced by PCR. Gateway cloning was made according to the manufacturer instructions (Invitrogen). The oligonucleotides used are listed in Table 1.

\section{Construction of an aphT resistance cassette}

Plasmid pFJS235 carrying the aminoglycoside 3'-phosphotransferase gene (which encodes for kanamycin resistance) devoid of its transcription terminator (aphT) was constructed as follows. Primer aphT.F, derived from pUC4K [27] and located 5 ' from the aph gene, and primer aphT.R, derived from the aph sequence [28], were used to amplify a 1,005 bp DNA fragment from plasmid pUC4K. The amplified fragment was digested with Pst I and cloned into pUC4K/PstI, yielding plasmid pFJS235. The aphT gene can be retrieved from pFJS235 by using PstI, HincII, SalI, or EcoRI.

\section{Construction of mutants and complementation plasmids}

To construct a polar $\Delta u r e T$ mutant $(\Delta u r e T p)$ from $B$. abortus strain 2308, ureT was replaced by aph. DNA fragments both upstream and downstream of ure $T$ were amplified with the following set of primers: U_BMEI0642_XbaI.F and U_BMEI0642_BamHI.R were used to amplify a region of 578 bp upstream of ureT (U_ureT) and D_BMEI0642_BglIIIF and D_BMEI0642_PstI.R were used to amplify a region of 589 downstream of ureT (D_ureT). PCR fragments of the expected size were gel-purified and cloned into $\mathrm{pGEM}^{\circ}$-T Easy resulting in plasmids pFJS225 and pFJS226 respectively. pFJS225 was linearized with BamHI and pFJS226 with BglII, and ligated to a $1.2 \mathrm{~kb} B a m \mathrm{HI}$ fragment from pUC4K, containing aph with its transcription terminator. An XbaI \&PstI fragment of $1.4 \mathrm{~kb}$ was obtained directly from the partially digested ligation mixture, and cloned into pDS132 digested with PstI and partially with XbaI, to obtain pFJS227b, that was used to construct the corresponding $\Delta u r e T p$ mutants in Brucella, as described below.

For the construction of a non-polar $\Delta u r e T$ mutant from B. abortus 2308, two PCR fragments of $578 \mathrm{bp}$ and $619 \mathrm{bp}$ were generated immediately upstream and downstream of the ureT gene with oligonucleotides U_BMEI0642_XbaI.F and U_BMEI0642_BamHI.R and 
Table 2: Bacterial strains and plasmids used in this study.

\section{Characteristics}

Reference

\section{Strains}

Brucella abortus

\begin{tabular}{lll}
\hline 2308 & Virulent laboratory strain & \\
\hline $2308 \Delta$ ureTp & 2308 ureT polar mutant & This work \\
\hline $2308 \Delta$ ureT & 2308 ureT non-polar mutant & This work \\
\hline $2308 \Delta$ nikO & 2308 nikO non-polar mutant & This work
\end{tabular}

Escherichia coli

\begin{tabular}{|c|c|c|}
\hline $\mathrm{DH} 5 \mathrm{a}$ & Standard E. coli cloning strain & {$[36]$} \\
\hline S17-1 $\lambda$ pir & Mobilizing donor for conjugation & {$[37]$} \\
\hline \multicolumn{3}{|l|}{ Plasmids } \\
\hline pGEM-T Easy & PCR cloning vector & Promega \\
\hline pRH016 & Gateway shuttle vector & {$[31]$} \\
\hline pDS132 & Suicide mobilizable plasmid & {$[38]$} \\
\hline pBBR1 MCS & Broad-host-range plasmid & [39] \\
\hline pFJS225 & U_ureT in pGEMT-Easy & This work \\
\hline pFJS226 & D_ureT in pGEMT-Easy & This work \\
\hline pFJS227b & $\Delta u r e T:: a p h$ in $\mathrm{pDS} 132$ & This work \\
\hline pFJS235 & pUC4K with aphT & This work \\
\hline pFJS236 & $\Delta$ ureT in pGEMT-Easy & This work \\
\hline pFJS237 & $\Delta$ nikO in pGEMT-Easy & This work \\
\hline pFJS238 & $\Delta$ UureT::aphT in pGEMT-Easy & This work \\
\hline pFJS239 & $\triangle n i k O:: a p h T$ in pGEMT-Easy & This work \\
\hline
\end{tabular}


Table 2: Bacterial strains and plasmids used in this study. (Continued)

\begin{tabular}{lll}
\hline pFJS241b & AureT::aphT in pDS132 & This work \\
\hline pFJS242b & AnikO::aphT in pDS132 & This work \\
\hline pFJS243 & ureT in pRH016 & This work \\
\hline pFJS244 & nikO in pGEMT-Easy & This work \\
\hline pFJS245 & nikO in pBBR1 MCS & This work \\
\hline
\end{tabular}

oligonucleotides D_BMEI0642.F and D_BMEI0642_PstI.R respectively. The reaction conditions for both PCRs were 30 cycles at $55^{\circ} \mathrm{C}$, and $45 \mathrm{sec}$ onds at $72^{\circ} \mathrm{C}$, using Vent polymerase. Both fragments (containing complementary regions) were ligated by overlapping PCR using oligonucleotides U_BMEI0642_XbaI.F and D_BMEI0642_PstI.R and Taq polymerase from Qiagen, for 25 cycles at $55^{\circ} \mathrm{C}$ and extension time of 1 minute at $72^{\circ} \mathrm{C}$. The resulting fragment containing the $u r e T$ deletion allele was gel-purified and cloned into pGEM ${ }^{\circ}$-T Easy to obtain pFJS236. A BamHI fragment from pFJS235 containing aphT was introduced into the BamHI site of pFJS236, resulting in plasmid pFJS238. An XbaI \& PstI fragment from this plasmid containing the replaced $u r e T$ gene was cloned into pDS132 digested with PstI and partially with $X b a \mathrm{I}$, resulting in plasmid pFJS241b, that was used to create the corresponding Brucella mutant as described below.

For the construction of a $\Delta n i k O$ non-polar mutant, two PCR fragments of $501 \mathrm{bp}$ and $499 \mathrm{bp}$ were generated immediately upstream and downstream of the nikO gene with oligonucleotides BAB1_1388_XbaI.F and RT_BAB1_1388.R, and oligonucleotides BAB1_1388_BglII.F and BAB1_1388_PstI.R respectively, using Vent polymerase. Both fragments (containing complementary regions) were ligated by overlapping PCR using oligonucleotides BAB1_1388_XbaI.F and BAB1_1388_PstI.R and Taq polymerase, and the resulting fragment containing the deleted $n i k O$ allele was cloned into pGEM $-\mathrm{T}$ Easy (pFJS237). A BamHI fragment from pFJS235 containing aphT was introduced into the BglII site of pFJS237, resulting in plasmid pFJS239. An XbaI \&PstI fragment from this plasmid containing the replaced nikO gene was cloned into pDS132 digested with PstI and partially with $X b a \mathrm{I}$, resulting in plasmid pFJS242b, that was used to create the corresponding Brucella mutant as described below.

To construct the different mutants, replacement plasmids were transformed into E. coli S17-1 $\lambda$ pir, and mobilized to the corresponding Brucella recipient strain, by mixing equal volumes $(100 \mu \mathrm{l})$ of liquid cultures of both donor and recipient cells on a $0.22-\mu \mathrm{m}$-pore-size filter. The filter was left for $4 \mathrm{~h}$ on a BA plate without antibiotics, soaked in PBS, and then different dilutions were plated onto BAF plates containing $\mathrm{Cm}$ and $\mathrm{Km}$. Colonies growing in this medium represented single-crossover events. Five colonies of each construct were pooled and grown in $\mathrm{BB}$, and $10^{8} \mathrm{CFU}$ were plated on $\mathrm{BA}$ containing $5 \%$ sucrose to select for the double crossover. Sucroseresistant colonies were replicated in BA Cm plates, and $\mathrm{CmS}$ colonies were selected and analyzed by PCR and southern blot to ensure that the right mutant had been constructed.

To complement the different mutants complementation plasmids were constructed as follows: ureT was cloned by using the Gateway recombination cloning technology (Invitrogen) [29]. The entry vector was obtained from the Brucella ORFeome generated previously [30]. The destination vector, pRH016 [31], carries a chloramphenicol resistance marker, and the toxic cassette is flanked by attR 1 and attR2 recombinational sites. The recombinational cloning procedure was performed as recommended by the manufacturer, to produce pFJS243. nikO was amplified by PCR with oligonucleotides nikO_SalI.F and nikO_PstI.R, cloned into pGEM-T Easy to obtain pFJS244, and then subcloned into pBBR1 MCS/ SalI \&PstI to give pFJS245. Both pFJS243 and pFJS245 were transformed into $E$. coli $\mathrm{S} 17-1 \lambda$ pir to be mobilized to Brucella. Complemented strains were selected in BAF $\mathrm{Cm}$.

\section{In vitro susceptibility of Brucella to acid $\mathrm{pH}$}

$B$. abortus strains were grown in $\mathrm{BB}$ until the end of the exponential phase, washed in sterile water and resuspended at a concentration of $10^{8} \mathrm{CFU} / \mathrm{ml}$ in citrate buffer pH 2.0 for $30 \mathrm{~min}$ in the presence or absence of different concentrations of urea. Bacteria were washed three times in phosphate-buffered saline (PBS), and survivors counted after dilution and plating. 


\section{Measurement of urease activity}

Urease activity was determined by measuring the amount of ammonia released from urea. Exponential cultures of bacteria grown in $\mathrm{BB}$, supplemented or not with $500 \mu \mathrm{M}$ of $\mathrm{NiCl}_{2}$ as indicated, were recovered by centrifugation, washed, and resuspended in PBS to a concentration of $10^{8} \mathrm{CFU} / \mathrm{ml}$. The preparations were then lysed using three 10-s cycles with a FastPrep system (Bio 101, Vista, $\mathrm{CA})$ at the maximum setting, cooled on ice, and centrifuged for $5 \mathrm{~min}$ at $25,000 \times \mathrm{g}$ at $4^{\circ} \mathrm{C}$ to remove the cell debris. Crude extracts were stored at $-80^{\circ} \mathrm{C}$ until they were used. For standard urease reactions, 5 to $10 \mu \mathrm{l}$ of extract were added to a tube containing $200 \mu \mathrm{l}$ of $50 \mathrm{mM}$ urea in $\mathrm{PBS}$ and incubated for $5 \mathrm{~min}$ at $37^{\circ} \mathrm{C}$. Urease activitiy was also measured in intact cells, in this case the pelleted bacteria were resuspended in $200 \mu \mathrm{l}$ of either PBS ( $\mathrm{pH} 7.7)$ or citrate buffer at different $\mathrm{pH}(3.8,4.2,4.6$, $5.0,5.4,5.8$, and 6.2), supplemented or not with urea at different concentrations $(0,1,5,10,20,30,40,50,75$, and $100 \mathrm{mM}$ ), and incubated at $37^{\circ} \mathrm{C}$ for 1 hour. The amount of ammonia released from urea hydrolysis was determined colorimetrically by the modified Berthelot reaction [32], and the total protein concentration was measured by a Bradford assay [33]. Urease specific activity was expressed in $\mu \mathrm{mol}$ of NH3 $\mathrm{min}^{-1} \mathrm{mg}^{-1}$ protein (for crude extracts) and pmol of $\mathrm{NH}_{3} \mathrm{~min}^{-1} \log 10 \mathrm{cfu}^{-1}$ (for intact cells).

\section{RNA isolation and reverse transcriptase PCR (RT-PCR)}

$3 \mathrm{ml}$ of a bacterial culture in mid-log phase $\left(\mathrm{OD}_{600}=0.6\right.$ $0.7)$ were stabilized with RNAprotect Bacteria Reagent (Qiagen). After harvesting the cells, they were resuspended in $300 \mu \mathrm{l}$ of TE containing lysozyme $1 \mathrm{mg} / \mathrm{ml}$, and incubated for $15 \mathrm{~min}$ at room temperature. They were treated with $15 \mu \mathrm{l}$ of $10 \%$ Zwittergent 3-16 (Calbiochem) and $6 \mu \mathrm{l}$ of $20 \mathrm{mg} / \mathrm{ml}$ of proteinase $\mathrm{K}$ for $1 \mathrm{~h}$ at $37^{\circ} \mathrm{C}$, and then total RNA was extracted with the RNeasy Mini System (Qiagen) in combination with the RNase-Free DNase Set (Qiagen). cDNA was generated by using Superscript III RT (Invitrogen) according to the manufacturer's protocol. $1 \mu \mathrm{l}$ of the resulting cDNA was used for each PCR. As a negative control, reactions were also run on RNA templates without RT treatment, and as a positive control, each reaction was also made with purified genomic DNA as template. The cycling parameters were 30 cycles of $94^{\circ} \mathrm{C}$ for $30 \mathrm{~s}, 55^{\circ} \mathrm{C}$ for $30 \mathrm{~s}$, and $72^{\circ} \mathrm{C}$ for $1.5 \mathrm{~min}$. The resulting amplicons were analyzed in $0.8 \%$ agarose gels. Primers were designed with Primer3 software [34].

\section{Genomic data and analysis}

The complete genome sequence and annotation of the $B$. abortus 2308 strain was obtained fron GenBank (Accession numbers AM040264 and AM040265 for chromosomes I and II respectively).
Blast comparisons against the microbial genome database were performed via web at the NCBI Blast server [35].

\section{Statistical analysis}

A statistical analysis was performed using Prism3, version 3.0(GraphPad Software, San Diego, CA). Statistical significance wascalculated using either a nonparametric Mann-Whitney test or an unpaired $t$ test. A $P$ value of < 0.05 was considered statistically significant.

\section{Authors' contributions}

FJS designed and supervised the work and wrote the paper. AC performed all the microbiological work and the different urease activity assays. AS did the transcriptional analysis of the urease operon. JMGL performed the genomic analysis and bioinformatic work and also wrote the paper.

\section{Acknowledgements}

This work was supported by grants BIO2007-63656 from the Spanish Ministerio de Educación y Ciencia, and API 07/01 from Fundación Marqués de Valdecilla to FJS.

We thank Matxalen Llosa and Olga Draper for critical reading and copyediting of the manuscript, Regis Hallez and Xavier de Bolle for providing plasmid pRH016, and Dominique Schneider for providing plasmid pDS132.

\section{Author Details}

Departamento de Biología Molecular, Universidad de Cantabria, and Instituto de Biomedicina y Biotecnología de Cantabria (IBBTEC), UC-CSIC-IDICAN, Santander, Spain

Received: 30 November 2009 Accepted: 10 April 2010

Published: 10 April 2010

\section{References}

1. Sangari FJ, Seoane A, Rodriguez MC, Aguero J, Garcia Lobo JM: Characterization of the urease operon of Brucella abortus and assessment of its role in virulence of the bacterium. Infect Immun 2007, 75(2):774-780

2. Bandara AB, Contreras A, Contreras-Rodriguez A, Martins AM, Dobrean V, Poff-Reichow S, Rajasekaran P, Sriranganathan N, Schurig GG, Boyle SM: Brucella suis urease encoded by ure 1 but not ure 2 is necessary for intestinal infection of BALB/c mice. BMC Microbio/ 2007, 7:57.

3. Marshall BJ, Barrett LJ, Prakash C, McCallum RW, Guerrant RL: Urea protects Helicobacter (Campylobacter) pylori from the bactericidal effect of acid. Gastroenterology 1990, 99(3):697-702.

4. Maroncle N, Rich C, Forestier C: The role of Klebsiella pneumoniae urease in intestinal colonization and resistance to gastrointestinal stress. Res Microbiol 2006, 157(2):184-193.

5. Young GM, Amid D, Miller VL: A bifunctional urease enhances survival of pathogenic Yersinia enterocolitica and Morganella morganii at low pH. J Bacteriol 1996, 178(22):6487-6495.

6. Burne RA, Chen Y-YM: Bacterial ureases in infectious diseases. Microbes and Infection 2000, 2(5):533-542.

7. Sebbane F, Bury-Mone S, Cailliau K, Browaeys-Poly E, De Reuse H, Simonet M: The Yersinia pseudotuberculosis Yut protein, a new type of urea transporter homologous to eukaryotic channels and functionally interchangeable in vitro with the Helicobacter pylori Urel protein. $\mathrm{Mol}$ Microbiol 2002, 45(4): 1 165-1174.

8. Tsolis RM, Seshadri R, Santos RL, Sangari FJ, Lobo JM, de Jong MF, Ren Q, Myers G, Brinkac LM, Nelson WC, et al:: Genome degradation in Brucella ovis corresponds with narrowing of its host range and tissue tropism. PLoS One 2009, 4(5):e5519.

9. Contreras-Rodriguez A, Quiroz-Limon J, Martins A, Peralta H, AvilaCalderon E, Sriranganathan N, Boyle S, Lopez-Merino A: Enzymatic, immunological and phylogenetic characterization of Brucella suis urease. BMC Microbiology 2008, 8(1):121.

10. Wattt RK, Ludden PW: Nickel-binding proteins. Cell Mol Life Sci 1999, 56(7-8):604-625 
11. Navarro C, Wu LF, Mandrand-Berthelot MA: The nik operon of Escherichia coli encodes a periplasmic binding-protein-dependent transport system for nickel. Mol Microbiol 1993, 9(6):1181-1191.

12. Rodionov DA, Hebbeln $P$, Eudes A, ter Beek J, Rodionova IA, Erkens GB, Slotboom DJ, Gelfand MS, Osterman AL, Hanson AD, et al:: A novel class of modular transporters for vitamins in prokaryotes. J Bacterio/ 2009, 191(1):42-51

13. Hebbeln $P$, Eitinger $T$ : Heterologous production and characterization of bacterial nickel/cobalt permeases. FEMS Microbiol Lett 2004 230(1):129-135.

14. Eitinger T, Suhr J, Moore L, Smith JA: Secondary transporters for nickel and cobalt ions: theme and variations. Biometals 2005, 18(4):399-405.

15. Hidalgo E, Palacios JM, Murillo J, Ruiz-Argueso T: Nucleotide sequence and characterization of four additional genes of the hydrogenase structural operon from Rhizobium leguminosarum bv. viciae. J Bacteriol 1992, 174(12):4130-4139.

16. Rodionov DA, Hebbeln P, Gelfand MS, Eitinger T: Comparative and functional genomic analysis of prokaryotic nickel and cobalt uptake transporters: evidence for a novel group of ATP-binding cassette transporters. J Bacteriol 2006, 188(1):317-327.

17. Jubier-Maurin V, Rodrigue A, Ouahrani-Bettache S, Layssac M, Mandrand Berthelot M-A, Kohler S, Liautard J-P: Identification of the nik Gene Cluster of Brucella suis: Regulation and Contribution to Urease Activity. J Bacterio/ 2001, 183(2):426-434.

18. Levin EJ, Quick M, Zhou M: Crystal structure of a bacterial homologue of the kidney urea transporter. Nature 2009, 462(7274):757-761.

19. Weeks DL, Eskandari S, Scott DR, Sachs G: A H+-gated urea channel: the link between Helicobacter pylori urease and gastric colonization. Science 2000, 287(5452):482-485.

20. Weeks DL, Gushansky G, Scott DR, Sachs G: Mechanism of proton gating of a urea channel. J Biol Chem 2004, 279(11):9944-9950.

21. Overbeek R, Begley T, Butler RM, Choudhuri JV, Chuang HY, Cohoon M, de Crecy-Lagard V, Diaz N, Disz T, Edwards R, et al.: The subsystems approach to genome annotation and its use in the project to annotate 1000 genomes. Nucleic Acids Res 2005, 33(17):5691-5702.

22. Spyropoulos IC, Liakopoulos TD, Bagos PG, Hamodrakas SJ: TMRPres2D: high quality visual representation of transmembrane protein models. Bioinformatics 2004, 20(17):3258-3260.

23. Delpino MV, Marchesini MI, Estein SM, Comerci DJ, Cassataro J, Fossati CA, Baldi PC: A bile salt hydrolase of Brucella abortus contributes to the establishment of a successful infection through the oral route in mice. Infect Immun 2007, 75(1):299-305.

24. Paixao TA, Roux CM, den Hartigh AB, Sankaran-Walters S, Dandekar S, Santos RL, Tsolis RM: Establishment of systemic Brucella melitensis infection through the digestive tract requires urease, the type IV secretion system, and lipopolysaccharide O-antigen. Infect Immun 2009, 77(10):4197-4208.

25. Sambrook J, Fritsch EF, Maniatis T: Molecular cloning: a laboratory manual. 2nd edition. Cold Spring Harbor, NY.: Cold Spring Harbor Laboratory Press; 1989.

26. Sangari FJ, Aguero J: Identification of Brucella abortus B19 vaccine strain by the detection of DNA polymorphism at the ery locus. Vaccine 1994, 12(5):435-438.

27. Vieira J, Messing J: The pUC plasmids, an M13 mp7-derived system for insertion mutagenesis and sequencing with synthetic universal primers. Gene 1982, 19(3):259-268.

28. Oka A, Sugisaki H, Takanami M: Nucleotide sequence of the kanamycin resistance transposon Tn903. J Mol Biol 1981, 147(2):217-226.

29. Walhout AJ, Temple GF, Brasch MA, Hartley JL, Lorson MA, Heuvel S van den, Vidal M: GATEWAY recombinational cloning: application to the cloning of large numbers of open reading frames or ORFeomes. Methods Enzymol 2000, 328:575-592.

30. Dricot A, Rual JF, Lamesch P, Bertin N, Dupuy D, Hao T, Lambert C, Hallez R, Delroisse JM, Vandenhaute J, et al:: Generation of the Brucella melitensis ORFeome Version 1.1. Genome Res 2004, 14(10B):2201-2206.

31. Hallez R, Letesson JJ, Vandenhaute J, De Bolle X: Gateway-based destination vectors for functional analyses of bacterial ORFeomes: application to the Min system in Brucella abortus. Appl Environ Microbiol 2007, 73(4):1375-1379.

32. Senior BW, Bradford NC, Simpson DS: The ureases of Proteus strains in relation to virulence for the urinary tract. J Med Microbio/ 1980 , 13(4):507-512.
33. Bradford MM: A rapid and sensitive method for the quantitation of microgram quantities of protein utilizing the principle of protein-dye binding. Anal Biochem 1976, 72:248-254.

34. Rozen S, Skaletsky H: Primer3 on the WWW for general users and for biologist programmers. Methods Mol Biol 2000, 132:365-386.

35. BLAST with microbial genomes [http://www.ncbi.n/m.nih.gov/sutils/ genom table.cgi

36. Hanahan D: Studies on transformation of Escherichia coli with plasmids. J Mol Biol 1983, 166(4):557-580.

37. Herrero M, de Lorenzo V, Timmis KN: Transposon vectors containing non-antibiotic resistance selection markers for cloning and stable chromosomal insertion of foreign genes in gram-negative bacteria. $J$ Bacteriol 1990, 172(11):6557-6567.

38. Philippe N, Alcaraz JP, Coursange E, Geiselmann J, Schneider D: Improvement of pCVD442, a suicide plasmid for gene allele exchange in bacteria. Plasmid 2004, 51(3):246-255.

39. Kovach ME, Phillips RW, Elzer PH, Roop RM, Peterson KM: pBBR1 MCS: a broad-host-range cloning vector. Biotechniques 1994, 16(5):800-802.

doi: $10.1186 / 1471-2180-10-107$

Cite this article as: Sangari et al., Brucella abortus ure2 region contains an acid-activated urea transporter and a nickel transport system BMC Microbiology 2010, 10:107

\section{Submit your next manuscript to BioMed Centra and take full advantage of:}

- Convenient online submission

- Thorough peer review

- No space constraints or color figure charges

- Immediate publication on acceptance

- Inclusion in PubMed, CAS, Scopus and Google Scholar

- Research which is freely available for redistribution

Submit your manuscript at www.biomedcentral.com/submit
C) Biomed Central 